\title{
Perirenal Hematomas Induced by Extracorporeal Shock Wave Lithotripsy (ESWL). Therapeutic Management
}

\author{
Apostolos P. Labanaris ${ }^{1, \star}$, Reinhard Kühn ${ }^{1}$, Günter E. Schott ${ }^{2}$, \\ and Vahudin Zugor $^{2}$ \\ ${ }^{1}$ Department of Urology, Martha Maria Medical Center, Academic Hospital of \\ Erlangen University, Nurnberg, Germany; ${ }^{2}$ Department of Urology, University of \\ Erlangen Medical Center, Erlangen, Germany \\ E-mail: labanaris@web.de
}

Received May 16, 2007; Revised July 29, 2007; Accepted August 14, 2007; Published September 17, 2007

Extracorporeal shock wave lithotripsy (ESWL) is nowadays accepted as the treatment of choice for the majority of patients with renal or proximal ureteral calculi. Although, a relatively noninvasive modality with low morbidity, minor or major complications can be noted. A relative severe complication for the patient and confusing for the treating physician is the perirenal hematoma. With review the literature and an example of perirenal hematoma induced by ESWL in a patient treated in our department, we describe its therapeutic management.

KEYWORDS: ESWL, perirenal hematoma, conservative management

\section{INTRODUCTION}

Extracorporeal shock wave lithotripsy (ESWL) is an effective, relatively noninvasive modality with low morbidity for the treatment of upper urinary tract calculi. First described clinically by Chaussy and associates in 1980[1], it is now accepted as the treatment of choice for the majority of patients with renal or proximal ureteral calculi. Numerous studies have been focused on the effectiveness, side effects, and complications of ESWL treatment. It is thought that the mechanism that plays a role in the development of the complications is the compressive and tensile forces of shockwaves directed at soft tissue, and the effect of cavitation on the individual cell integrity[2]. Although the majority of complications relate to the passage of stone fragments, including severe pain and ureteral obstruction, renal or perirenal hematomas are a well-known complication of ESWL.

We review the literature and present an example of perirenal hematoma induced by ESWL and its therapeutic management.

\section{CASE REPORT}

In January 2006, a 46-year-old man presented to our department with a history of a left kidney stone and was scheduled for ESWL. His past medical history revealed no contraindications to ESWL, which include 
bleeding tendencies, uncontrolled hypertension, active urinary tract infection, kidney disease, morbid obesity, or anatomic abnormalities of the urinary tract. The procedure was performed with a permanently installed third-generation lithotripter. After intravenous sedation of the patient, ESWL treatment began with a final shockwave number of 3000 and a voltage range of $15 \mathrm{kV}$. During the procedure and the first $24 \mathrm{~h}$ afterwards, no pain or gross hematuria were reported by the patient. The following day, the patient reported mild pain in the left flank. The patient denied nausea, vomiting, chest pain, or shortness of breath. Physical examination revealed a middle-aged man in moderate distress due to pain. Vital signs were: temperature, $36.6^{\circ} \mathrm{C}$; blood pressure, $121 / 71 \mathrm{~mm} \mathrm{Hg}$; heart rate, 68 beats $/ \mathrm{min}$; and respiratory rate, 18 breaths/min. The heart was regular without murmurs and lungs were clear to auscultation. The abdomen was soft and nontender to palpation. Back examination revealed left flank percussion tenderness at the costovertebral angle. No bruising was present. Laboratory studies revealed hemoglobin of $12.1 \mathrm{~g} / \mathrm{dl}$ and a white blood cell count of $14 \mathrm{k} / \mathrm{Ul}$. Urinalysis was significant for 100-150 red blood cells. Sonography revealed a large hematoma of the left kidney with probable rupture into the retroperitoneum. Due to the sonographic results, a computed tomography (CT) scan of the abdomen was ordered (Fig. 1). The CT scan verified the sonographic results. Creatinine levels were pre- and postoperative 0.8 and 0.76 $\mathrm{mg} / \mathrm{dl}$, respectively. The size of the hematoma was approximately $12 \times 16 \times 8 \mathrm{~cm}$. Over the following 36 $\mathrm{h}$, the patient was noted to have a drop in his hemoglobin to $7.7 \mathrm{~g} / \mathrm{dl}$. Blood transfusion was required. On the third hospital day, the patient became hemodynamically stable with a rise in his hemoglobin to 11.3 $\mathrm{g} / \mathrm{dl}$. A repeat CT scan of the abdomen did not reveal change in the size of the hematoma. By the fifth hospital day, the hemoglobin became stable and the patient's pain had significantly improved. He was discharged from the hospital without any kind of surgical intervention. Up to the present day, the patient has not presented hypertension secondary to renal compression or abnormal creatinine levels.

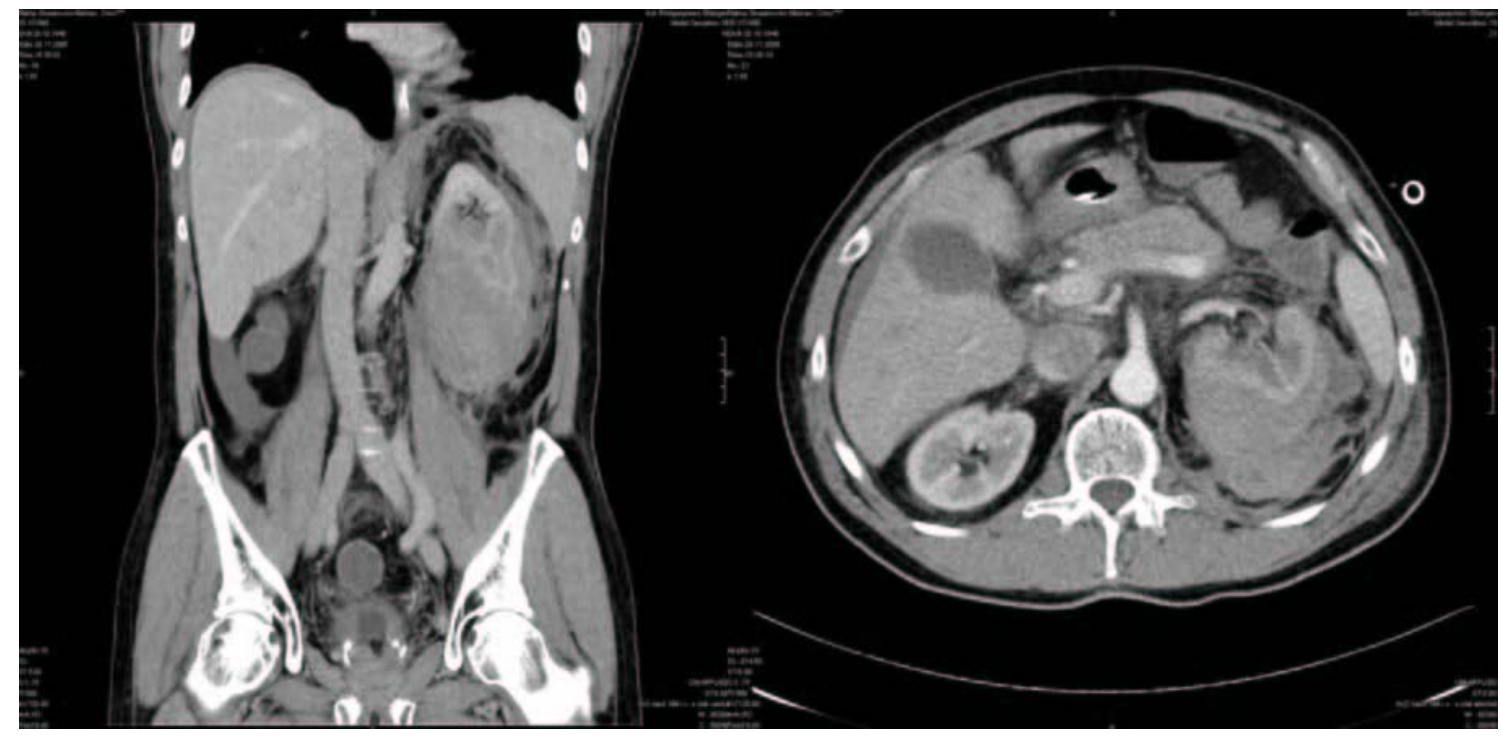

FIGURE 1. CT of a left perirenal hematoma.

\section{DISCUSSION}

ESWL is an effective, relatively noninvasive modality accepted as the treatment of choice for the majority of patients with renal or proximal ureteral calculi. Nevertheless, minor or major complications can be noted. In order to avoid or to lower the incidence of these complications, proper selection of the candidates should be achieved with strict respect to the contraindications to ESWL. These include bleeding tendencies, pregnancy, uncontrolled hypertension, active urinary tract infection, morbid obesity, 
and anatomic abnormalities of the urinary tract. Major complications following ESWL are rare. The most frequent effect is microhematuria. ESWL treatment induces microtrauma and microscopic hemorrhage in normal kidneys[3,4,5]. Perinephric hematoma formation and infection, including acute pyelonephritis, are other known complications[2]. Indeed, the risk of peri- or intrarenal hematomas is estimated to be between 0.1 and $0.6 \%$ using ultrasonography[6,7,8], and between 20 and $25 \%$ using magnetic resonance imaging or CT[9,10]. The incidence, though, of clinically significant hemorrhage is less than $1 \%[11]$.

No clear correlation has been demonstrated between the number of shockwaves or the intensity supplied and the incidence of hematomas[9]. Predisposing factors include untreated arterial hypertension, coagulation deficits, and the use of antiplatelet drugs[11,12,13].

In the majority of cases of post-ESWL subcapsular hematomas, renal function is preserved and spontaneous radiographic resolution occurs within 2 years[14]. Coagulation disorders seem to correlate with the size of the hematoma rather than with the risk of its development[15].

The key to successful management of patients with renal trauma is an accurate assessment of the extent of renal injury. Proponents of a nonoperative approach believe that the majority of renal parenchymal injuries will heal without surgical exploration[16,17]. Skolarikos et al.[18] performed a literature search with the Medline database on ESWL between 1980 and 2004, reviewing 3,937 abstracts and reading 220 papers in full. They noted that treatment of the hematomas is conservative in most cases. The most likely outcome is spontaneous radiographic resolution of the hematoma within 2 years without clinically evident adverse effects on blood pressure or renal function.

Emergency renal exploration will still be required in the presence of hemodynamic instability despite appropriate resuscitation[19]. The most important late complication of a nonoperative approach is the Page kidney. The term "Page kidney" refers to the occurrence of hypertension secondary to renal compression usually associated with a perinephric or subcapsular hematoma. This phenomenon was first described by Page in 1939[20]. The first clinical case was described in 1955, in a patient who developed hypertension and was subsequently found to have a subcapsular hematoma[21].

The underlying pathophysiology is thought to result from renal ischemia and hypoperfusion, which consequently activates the renin-angiotensin-aldosterone system[22]. There are many possible causes of Page kidney, such as hematomas associated with trauma, iatrogenic, anticoagulants, and even associated with nonhematomas, such as large simple cysts. The time from injury to the onset of hypertension ranges from days to decades, with a mean of 36 months[23].

There is some evidence to suggest that renal trauma-induced hypertension is probably overestimated, and it is difficult to know if pre-existing essential hypertension might be a contributory factor[24].

At present, there are no definitive guidelines for the management of Page kidney. Previously, the management focused on surgical intervention. However, nowadays, conservative management is the usual recommended first-line treatment in such cases. With improvements in the range of oral antihypertensives, conservative treatment is more efficient and can provide a good quality of life for the patient[25]. In the event of persistent hypertension that is not responsive to treatment, surgical decompression might be required. There are two main aims of treatment: to decompress the subcapsular hematoma and to remove the fibrocollagenous shell.

\section{CONCLUSION}

Renal and perirenal hematomas induced by ESWL should be managed with a nonoperative approach, since the majority of renal parenchymal injuries will heal without surgical exploration. Emergency renal exploration is required only in the presence of hemodynamic instability despite appropriate resuscitation.

\section{REFERENCES}

1. Chaussy, C.H., Brendel, W., and Schmidt, E. (1980) Extracorporally induced destruction of kidney stones by shock 
waves. Lancet 2, 1265-1268.

2. Lingeman, J.E., Woods, J., Toth, P.D., Evan, A.P., and McAteer, J.A. (1989) The role of lithotripsy and its side effects. J. Urol. 141, 793-797.

3. Baumgartner, B.R., Dickey, K.W., Ambrose, S.S., Walton, K.N., Nelson, R.C., Bernardino, M.E. (1987) Kidney changes after extracorporeal shock wave lithotripsy: appearance on MR imaging. Radiology 163, 531.

4. $\quad$ Lingeman, J.E., Smith, L.H., Woods, J.R., and Newman, D.M., Eds. (1989) Urinary Calculi: ESWL, Endourology and Medical Therapy. Lea \& Febiger, Philadelphia.

5. $\quad$ Eisenberger, F., Miller, K., and Rassweiler, J., Eds. (1991) Stone Therapy in Urology. Thieme, Stuttgart.

6. $\quad$ Cass, A.S., Brooker,W., Duthoy, E., et al. (1992) Clinically diagnosed renal hemorrhage after ESWL with Dornier HM3 and Medstone lithotripters. J. Endourol. 6, 413.

7. Knapp, P.M., Kulb, T.B., Lingeman, J.E., Newman, D.M., Mertz, J.H., Mosbaugh, P.G., Steele, R.E. (1987) Extracorporeal shock wave induced perirenal hematomas. J. Urol. 137, 700.

8. Chaussy, C., Schuller, J., Schmiedt, E., Brandl, H., Jacham, D., and Liedl, B. (1984) Extracorporeal shock wave lithotripsy for treatment of urolithiasis. Urology 23, 59.

9. Rubin, J.I., Arger, P.H., Pollack, H.M., Banner, M.P., Coleman, B.G., Mintz, M.C., and Van Arsdalen, K.N. (1987) Kidney changes after extracorporeal shock wave lithotripsy: CT evaluation. Radiology 162, 21.

10. Kaude, J.V., Williams, C.M., Millner, M.R., Scott, K.N., and Finlayson, B. (1985) Renal morphology and function immediately after extracorporeal shock wave lithotripsy. AJR Am. J. Roentgenol. 145, 305.

11. Newman, L.H. and Saltzman, B. (1991) Identifying risk factors in development of clinically significant post-shockwave lithotripsy subcapsular hematomas. Uro1ogy 38, 35-38.

12. Ruiz, H. and Saltzman, B. (1990) Aspirin induced bilateral renal hemorrhage after extracorporeal shock wave lithotripsy: implications and conclusions. J. Urol. 143, 791.

13. Economacos, G., Loukas, S., Montzouratos, D., and Dimopoulos, C. (1987) Extracorporeal shock wave lithotripsy and blood clotting defects. J. Urol. 138, 630.

14. Krishnamurthi, V. and Streem, S.B. (1995) Long-term radiographic and functional outcome of extracorporeal shock wave lithotripsy induced perirenal hematomas. J. Urol. 154, 1673-1675.

15. Collado Serra, A., Huguet Perez, J., Monreal Garcia de Vicuna, F., Rousaud Baron, A., Izquierdo de la Torre, F., and Vicente Rodriguez, J. (1999) Renal hematoma as a complication of extracorporeal shock wave lithotripsy. Scand. J. Urol. Nephrol. 33(3), 171-175.

16. Peterson, N.E. (1989) Complications of renal trauma. Urol. Clin. North Am. 16, 221-236.

17. Smith, E.C., Elder, J.S., and Spirnak, J.P. (1993) Major blunt renal trauma in the pediatric population: is a nonoperative approach indicated? J. Urol. 149, 546-548.

18. Skolarikos, A., Alivizatos, G., and de la Rosette, J. (2006) Extracorporeal shock wave lithotripsy 25 years later: complications and their prevention. Eur. Urol. 50(5), 981-990.

19. Moudouni, S.M., Hadj Slimen, M., Manunta, A., Patard, J.J., Guiraud, P.H., Guille, F., Bouchot, O., and Lobel, B. (2001) Management of major blunt renal lacerations: is a nonoperative approach indicated? Eur. Urol. 40(4), 409414.

20. Page, I.H. (1939) The production of persistent arterial hypertension by cellophane perinephritis. JAMA 113, 20462048.

21. Engel, W.J. and Page, I.H. (1955) Hypertension due to renal compression resulting from subcapsular hematoma. $J$. Urol. 73, 735-739.

22. Davies, M.C. and Perry, M.J. (2006) Urological management of 'page kidney'. BJU Int. 98(5), 943-944.

23. Santucci, R.A., Wessells, H., Bartsch, G., et al. (2004) Evaluation and management of renal injuries: consensus statement of the renal trauma subcommittee. BJU Int. 93, 937-954.

24. Monstrey, S.J., Beerthuizen, G.I., van der Werken, C., Debruyne, F.M., and Goris, R.J. (1989) Renal trauma and hypertension. J. Trauma 29, 65-70.

25. Haydar, A., Bakri, R.S., Prime, M., and Goldsmith, D.J. (2003) Page kidney - a review of the literature. J. Nephrol. 16, 329-333.

\section{This article should be cited as follows:}

Labanaris, A.P., Kühn, R., Schott, G.E., and Zugor, V. (2007) Perirenal hematomas induced by extracorporeal shock wave lithotripsy (ESWL). Therapeutic management. TheScientificWorldJOURNAL 7, 1563-1566. DOI 10.1100/tsw.2007.236. 


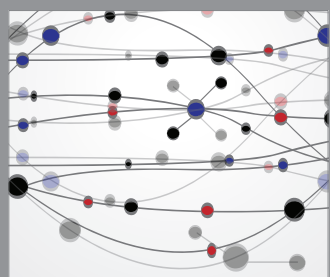

The Scientific World Journal
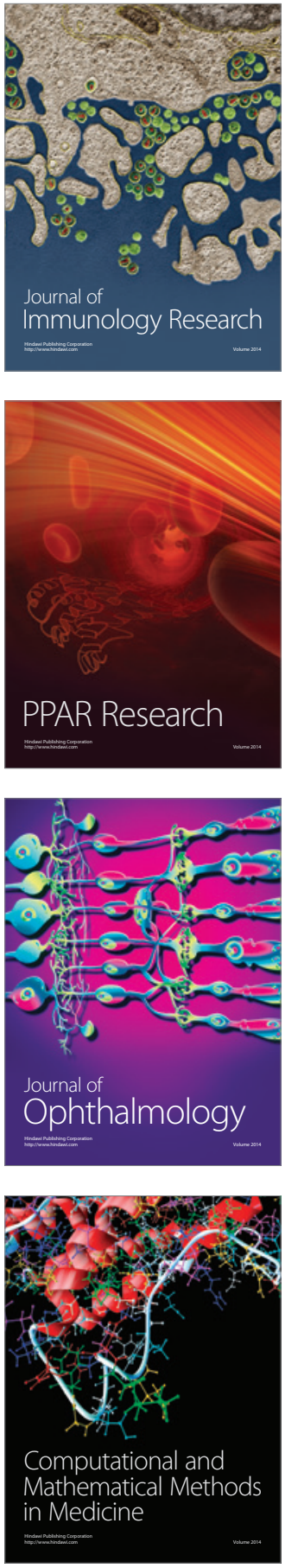

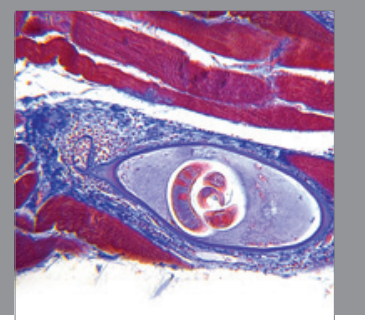

Gastroenterology

Research and Practice
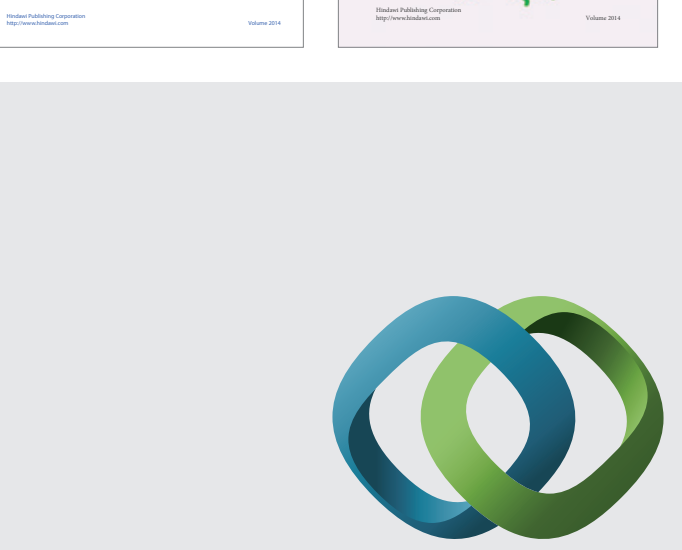

\section{Hindawi}

Submit your manuscripts at

http://www.hindawi.com
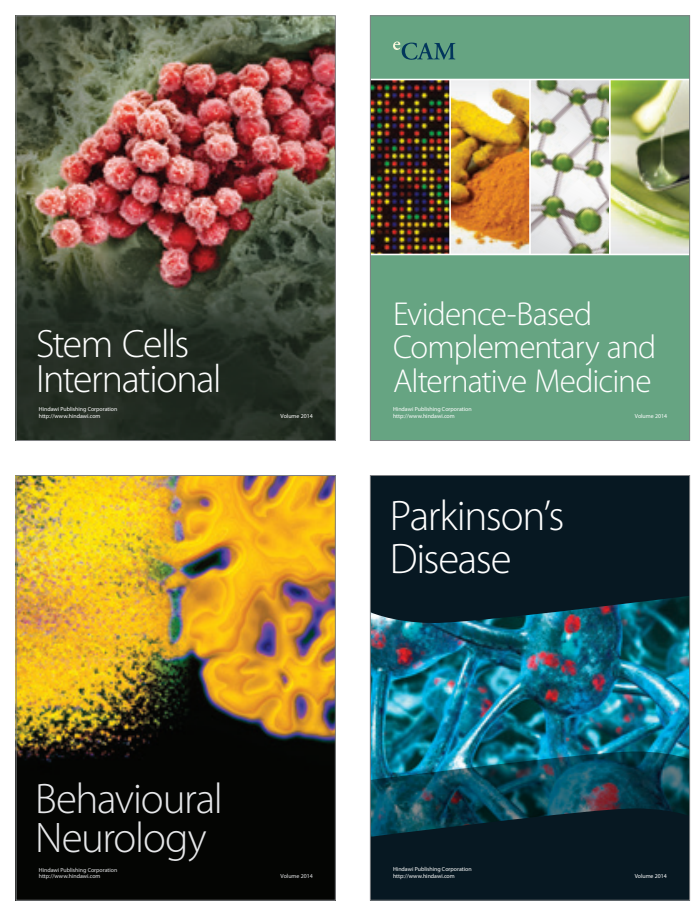

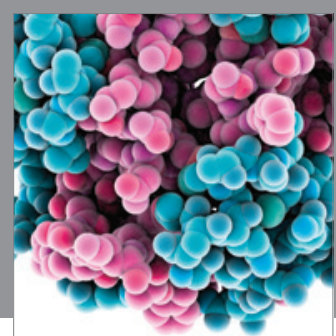

Journal of
Diabetes Research

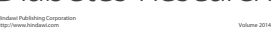

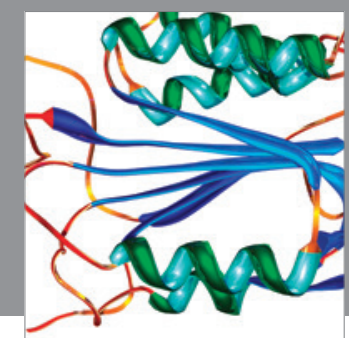

Disease Markers
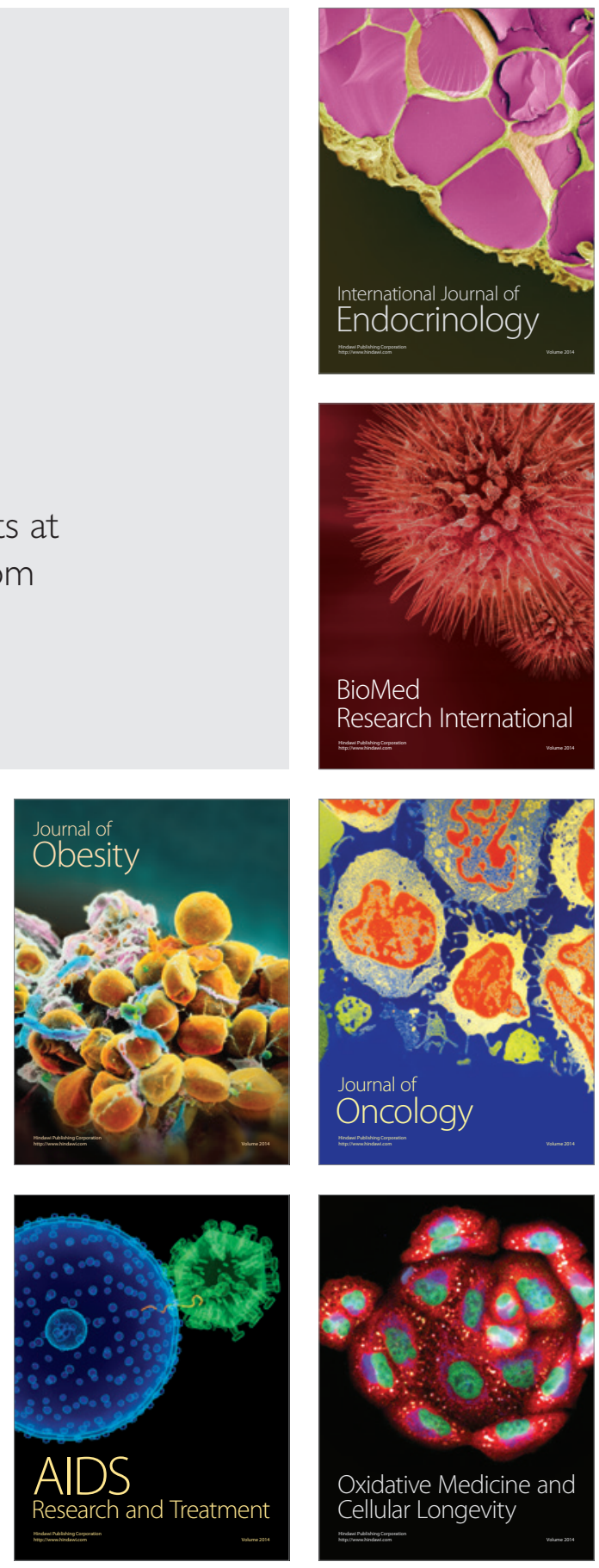